\title{
Model and observed statistics of California earthquakes parameters
}

\author{
M. Caputo $(*)$ - R. Console $(*)$ \\ Received on May 5 th, 1978.
}

\begin{abstract}
Riassunto - Il modello proposto da Caputo per la statistica dei parametri dei terremoti in una zona sismica viene confrontato con i dati disponibili per la California. Tali dati provengono dal lavoro di Thatcher e Hanks e da quelli di Tucker e Brune. In essi sono riportate le serie di parametri $M, M_{0}, l$ e $\Delta p$ osservati sperimentalmente. Per entrambe le serie di parametri vengono calcolate le distribuzicni statistiche e i risultati sono confrontati fra loro per mezzo delle relazioni imposte dalla teoria. I risultati, compatibilmente con le incertezze sperimentali e la scarsezza dei campioni adoperati, sembrano confermare la teoria e permettono di valutare la distribuzione per i parametri delle faglie che danno origine ai terremoti nella California.
\end{abstract}

SUMmarY - The model proposed by Caputo for the statistics of the earthquake parameters in a seismic region is compared with the data available for the California earthquake. Such data come from the work of Thatcher and Hanks and from those of Tucker and Brune. In them the series of parameters experimentally observed $M, M_{0}, l$, and $\Delta p$, are reported. For both series, the statistical distributions of the parameters are computed and the results are compared among themselves by means of the relations according to the theory. The results, within the limits of the experimental errors and the scarsity of the samples used, seem to confirm the theory and allow us to estimate the distribution for the parameters of faults originating earthquakes in California.

\section{INTRODUCTION.}

Recently several mechanical and mathematical models for the magnitude statistics of the earthquakes have been proposed (Very and

(*) Istituto di Fisica - Università degli Studi. - Roma. Istıtuto Nazionale di Geofisica - Roma. 
Jones, Burridge and Knopoff 1967). At the same time new concepts and new parameters have been introduced in seismology (Keilis Borok 1959, Brune 1973). The problem of the statistics by the introduction of unified models for all directly observed or indirectly obtained parameters has been so proposed again. Unified models explaining the empirical laws so far used in seismology for the earthquake statistics (Ranalli 1974, Chinnery and North 1975) have been proposed by Caputo $(1976,1977)$ for statistics both of magnitude and seismic moment observed in single seismic regions. For single seismic regions one means zones where the coefficient $\bar{A}_{2}$ of the empirical law $\log \bar{n}=\bar{A}_{2}+\bar{B}_{2} M$ for unit area is greater than a given threshold and the coeflicient $B_{2}$ doesn't change expressively for further subdivisions of the area (Caputo and Postpischl 1974). When these models were proposed, only data concerning magnitude for many seismic regions of the wcrld and only few data for the seismic moment referring to the whole world were available for a global check of the statistics for magnitude and seismic moment.

Therefore, the checks of the model carried out for average values of the wor'd although reliable (Caputo 1976, 1977) were not satisfactory because the model is valid only for single regions.

Data allowing more reliable checks of the models used have now become available (Thacher and Hanks 1973, Tucker and Brune 1973, 1977). They permit also to draw interesting conclusions about the geophysical and geological characteristics of the regions concerning the data.

Some of the geophysical and geological results obtained in this paper with statistical analysis of the data are independent of the model used and the sample of data. On the contrary, some results depend on the completeness of the sample used.

THE MODEL.

In the present paper the statistical model proposed by Caputo (1976, 1977) is used. In it part of the Earth's crust is considered as traversed by a system of faults of linear dimensions $l$ in which an elastic pressure of linear progress in time accumulates. When the pressure $p$ accumulated on a fault of the system reaches the limit of resistance, 
the earthquake occurs and in it, as a result of the release of energy, the pressure decreases by value $p-p_{0}=\Delta p$. The energy released by the quake in the form of elastic waves is given by:

$$
E=\frac{\eta k}{2 \mu} l^{3} \Delta p^{2}
$$

and the seismic moment by:

$$
M=\frac{l^{3} \Delta p}{c}
$$

where $\eta$ is the efficiency of the transformation of the released into elastic waves, $\mu$ is the rigidity of the medium, $k$ and $c$ are geometrical factors. For a circular fault one has $l=$ radius of the fault, $k=16 / 7$ and $c=7 / 16$.

Earthquake magnitude $M$ is generaliy regarded as depending on the energy released in the relation

$$
E=10^{\beta+\gamma M}
$$

where $\beta$ and $\gamma$ are characteristic parameters of the zone considered. In this way both $M$ and $M_{0}$ assume a value univically determined by the position of the event in the piano $l, \Delta p$.

From [1], [2], and [3] we have:

$$
\log M_{0}=\gamma M+\beta-\log \left(\frac{\eta k c}{2 \mu}\right)-\log \Delta p .
$$

The theory assumes then that the number of faults of the system with linear dimensions comprised between $l$ and $l+d l$ and stress drop comprised between $p$ and $p+d p$ be

$$
D(l)=D l^{-\nu} \Delta p^{\alpha-1} .
$$

Integration on the plane $(l, \Delta p)$ between the extreme values $l_{1}, l_{2}$ and $p_{1}, p_{2}$ permits us to establish that between the suitable limits $M_{1}<M<M_{2}$ and $M_{01}<M<M_{02}$ we have the following inear relations:

$$
\log \bar{n}=\bar{A}_{2}+\bar{B}_{2} M
$$




$$
\log \bar{n}_{0}=\bar{A}_{02}+\bar{B}_{02} \log M_{0}
$$

where $\bar{n}$ and $\bar{n}_{0}$ represent the distribution density of the number of earthquakes depending on magnitude and seismic moment.

For the cumulative distributions we have:

$$
\begin{gathered}
\log n=A_{2}+B_{2} M \\
\log n_{0}=A_{02}+B_{02} \log M_{0} .
\end{gathered}
$$

For the distribution coefficients there are the following relations: (Caputo 1978):

$$
\begin{gathered}
A_{02}=A_{2}+\frac{\nu-1}{3} \log \left(\frac{2 \mu 10^{\beta}}{\eta k c}\right)+-\log \frac{3 \alpha+2(\nu-1)}{3 \alpha+\nu-1}- \\
-\log \frac{p_{2}^{a+\frac{2}{3}}{ }^{\nu-1)}-p_{1}^{a+\frac{2}{3}(\nu-1)}}{p_{2}^{a+\frac{\nu-1}{v}}-p_{1}^{a+\frac{\nu-1}{3}}} \\
\bar{B}_{02}=\frac{\bar{B}_{2}}{\gamma}=\frac{\nu-1}{3}
\end{gathered}
$$

If we consider a region in which elastic pressure accumulates during time 7 , at the rate of $\varepsilon$ per year, and in which this pressure is released through earthquakes on faults distributed statistically according to [5] we have the following relation (Caputo 1978):

$$
\log D \varepsilon T=A_{02}+\log \left[\left(\alpha+\frac{v-1}{3}\right)(\nu-1) c^{\frac{\nu-1}{3}}\left(p_{2^{\frac{\nu-1}{3}}+\alpha}-p_{1}^{\frac{\nu-1}{3}}\right)^{-1}\right]
$$

By means of these relations, therefore, it is possible to determine the number of faults in a region setting out on statistically observable quantities.

Analyses of the California data.

The analyses concern two groups of data: one of California 
earthquakes (Thatcher \& Hanks, 1973) and one of a series of quakes following the violent San Fernando (California) event (Tucker \& Brune 1973, 1977). Both quake series are described by four parameters: magnitude $M$, seismic moment $M_{0}$, linear dimension of the fault that caused the earthquake, $l$, and its stress drop, $\Delta p ; M, M_{0}$ and $l$, in these parameters, come from direct observation, $\Delta p$ is obtained from [2]; moreover, they must satisfy the relations [1] and [3].

The three quantities observed in the papers cited are the local magnitude $M_{l}$, the corner frequency $f_{0}$ of the spectrum, and the amplitude $\Omega_{0}$ at low frequencies.

We shall first analyse the sample of data of Thatcher and Hanks which is more numerous since it has the above mentioned parameters for 138 events.

The four parameters series observed and deduced $\left(M, M_{0}, \Delta p, l\right)$ where analysed separately, and a histogram was determined for each (Figs. 1-4). Fig. 5 representing in the p!ane $l, \Delta p$ the data of Thatcher

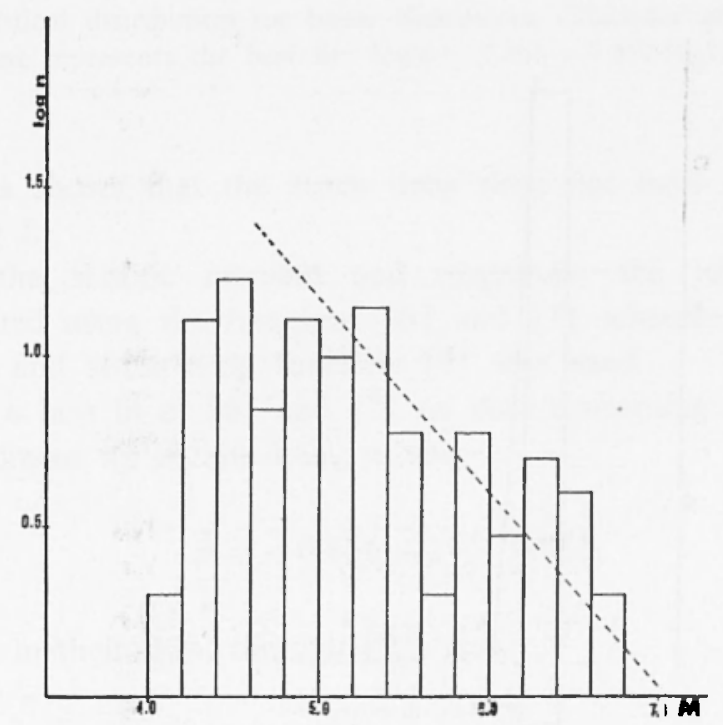

Fig. 1. Statistical distribution for magnitude (Thatcher and Hanks, 1973). The linc represents the best fit: $\log n=3.640-0.521 \mathrm{M}$. 


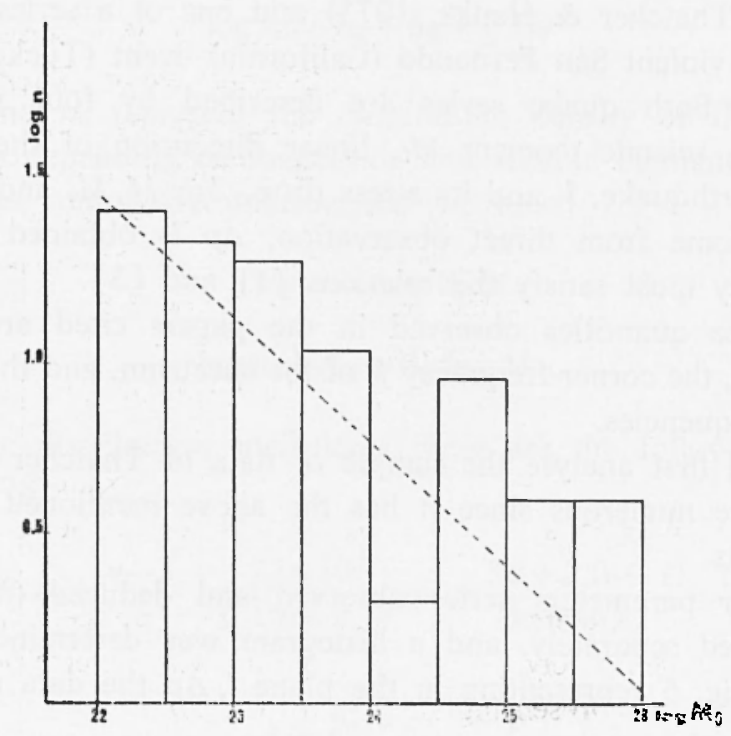

Fig. 2. Statistical distribution for seismic moment (Thatcher and Hanks, 1973). The line represents the best fit: $\log n_{3}=9.530-0.365 \log M_{0}$.

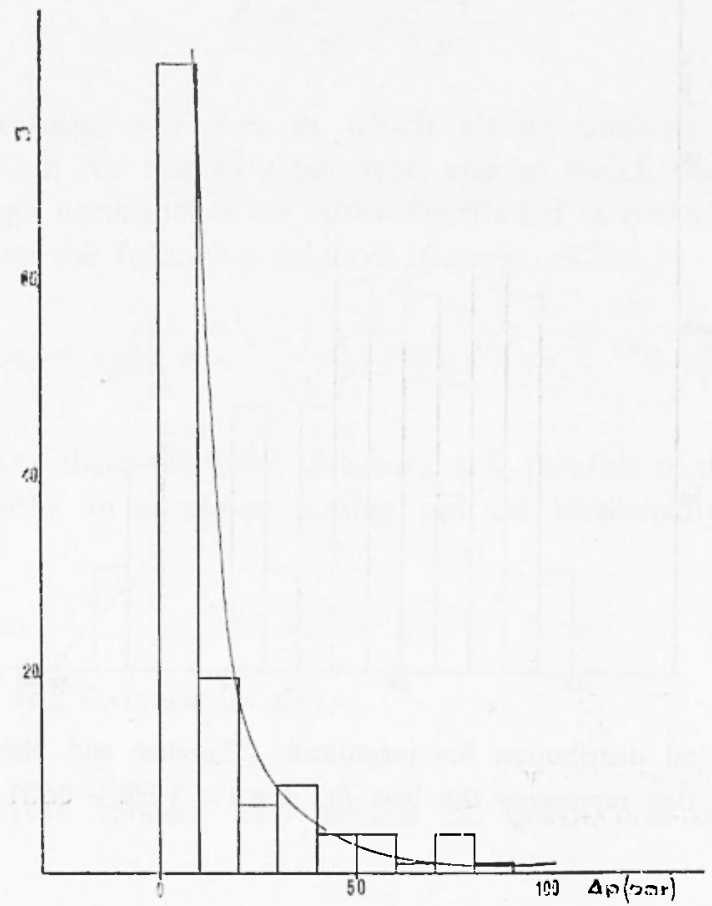

Fig. 3. Statistical distribution for stress drop (Thatcher and Hanks, 1973). The line represents the best fit: $\log n=4.135-1.988 \log \Delta p$. 


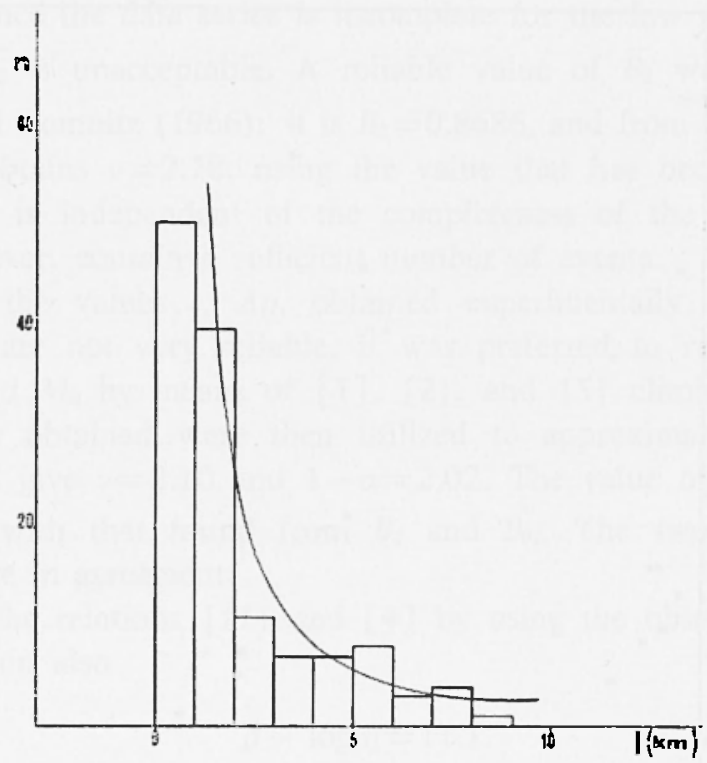

Fig. 4. Statistical distribution for linear dimensions (Thatcher and Hanks. 1973). The line represents the best fit: $\log n=2.193-1.617 \log l$.

and Hanks shows that the stress drop does not have any preference concerning $l$.

For the seismic moment and magnitude the histograms were approximated using the functions [6] and [7] whereas for the linear dimension and stress drop function [5] was used.

With a best fit of [6] and [7] on data concerning magnitude and seismic moment we obtained the values:

$$
\bar{B}_{2}=-0.521 \quad \bar{B}_{02}=-0.365
$$

$\bar{B}_{2}$ and $\bar{B}_{02}$ in their turn, through [9], give

$$
\gamma=1.43 \text { and } \nu=2.09
$$

A best fit of [5] for the data concerning $l$ gives $\nu=1.62$ and a best fit for the data concerning $\Delta p$ gives $1-\alpha=1.99$. A best fit of [4] for 




Fig. 5. California events (Tatcher and Hanks, 1973) represented in the plane $l, \Delta p$.

the data concerning $M$ and $M_{0}$ give:

$$
\log M_{0}=1.46 M+16.04
$$

in agreement with the value of $\gamma$ from $\bar{B}_{2}$ and $\bar{B}_{02}$. 
The values found for $\nu, \gamma, \bar{B}_{2}, \overline{B_{02}}$ satisfy [4], [6], J7], and [8], but since the data series is incomplete for the low magnitudes, the value of $\bar{B}_{2}$ is unacceptable. A reliable value of $\bar{B}_{2}$ was obtained by Epstein and Lomnitz (1966): it is $B_{2}=0.8686$, and from it, by means of [9], one obtains $\nu=2.78$, using the value that has been found for $\gamma$ and which is independent of the completeness of the catalogue that must, however, contain a sufficient number of events.

Since the values $l, \Delta p$, obtained experimentally by the corner frequency, are not very reliable, it was preferred to recalculate them from $M$ and $M_{0}$ by means of [1], [2], and [3] eliminating. E. The values thus obtained were then utilized to approximate [5] with a best fit and give $\nu=2.10$ and $1-\alpha=2.02$. The value of $\nu$ is in better agreement with that found from $\bar{B}_{2}$ and $\bar{B}_{02}$. The two values found for $1-\alpha$ are in agreement.

From the relations [11] and [4] by using the observed values of $\Delta p$ we obtain also

$$
\beta-\log \eta=11.1 .
$$

To obtain the distribution [5] we have to estimate $D$; using [10] and [9] with the value of $A_{2}=4.964$ of Epstein and Lomnitz, $T=1$ year and the value $10^{\beta} / \eta=11.1$ we obtain $\log D \varepsilon=16.9$. A tentative value of $D$ can then be obtained by assuming for $\varepsilon$ the secular value obtained from the strain observed at the surface.

The data of Tucker and Brune consist of the set of parameters $M_{0}, l$, and $\Delta p$ for 155 events. The magnitude has been estimated for only 40 of these events.

The data are characterized by the fact that they are part of a sequence of the 1971 San Fernando (California) earthquake.

A best fit of the formula [5] gives $\nu=3.47$ and $1-\alpha=1.62$.

Formula [4] gives

$$
\log M_{0}=1.52 M+16.08
$$

Formulae [6] and [7] give $\bar{B}_{2}=0.69$ and $\bar{B}_{02}=0.47$.

From $\bar{B}_{2}$ and $\bar{B}_{02}$ we obtain $\gamma=1.47$ which is in agreement with the value of [13]. From [13] and [4], by using the observed values of $\Delta p$, we obtain

$$
\beta-\log \eta=12.0 \text {. }
$$


The values here obtained for the parameters $\alpha, \nu, \gamma, \beta-\log \eta$ are in agreement with those found from the data of Thatcher and Hanks. The only value which is remarkably different is $\nu$ which is much higher than normal. This is typical of aftershock sequences as noted by other authors (e. g. see Caputo, 1979).



Fig. 6. California events represented in the plane $M, \log M_{0}$. Data of Thatcher and Hanks as dots, data of Tucker and Brune as stars. 
The data of Tucker and Brune is too scarse to allow a tentative estimate of $D \varepsilon$.

\section{Conclusions.}

The analysis presented in this paper confirms the validity of the model and its capability to estimate the distribution of the number of faults and of the stress drops. However, more complete sets of data also for other regions of the world would be desirable to confirm the validity of the model also in the range of large magnitudes and its capability to estimate tentative values of the maximum magnitude possible in the seismic region.

The analysis of this paper confirm also that in aftershock sequences there is larger partecipation of small faults.

\section{REFERENCES}

Brune, J. N., 1970. - Tectonic stress and the spectra of seismic shear waves. «J. Geophys. Res. », 75, pp. 4997-5009.

Burridge, R. and KNOPOFF, L., 1967. - Model and theoretical seismicity. "Bull. Seism. Soc. An. », 57, pp. 341-371.

Caputo, M., 1976. - Mechanical models of earthquakes and their statistics. Proc. E.S.C. Symposium on Earthquake Risk for nuclear Power Plant (1975), Roy. Neth. Meteorol. Inst. Publ. 153.

CAPUTO, M., 1977. - A mechanical model for the statistics of earthquakes magnitude, moment, and fault distribution. "Bull. Seism. Soc. Am.", 67, pp. 849-861.

Caputo, M., 1979. - A multiparameter physical model for the representation of regional seismicity.

Caputo, M. and PostPischl, D., 1974. - Contour mapping of seismic areas by numerical filtering and geological implications. "Ann. Geofis.», (Rome), 27.

Chinnery, M. A. and North, R. G., 1975. - The frequence of very large earihquakes. "Science ", pp. 1197-1198.

KeIlis-BoRoK, V. I., 1959. On estimation of the displacement in an earthquake source and source dimensions. "Ann. Geofis", (Rome), 12, pp. 205-214. 
RANALL1, G., 1974. - A test of lognormal distribution of earthquakes magnitude. Presented to the International Symposium on Seismology and Physics of the Solid Earth, Jena, April 1974.

ThATChER. W. and HANKs, T. C., 1973. - Source parameters of southern California earthquakes. «J. Geophys. Res.», 78, pp. 8547-8576.

Tucker, B. E. and Brune, J. N., 1973. - Seismograms, S-wave spectra, and source parameters for aftershocks of San Fernando earthquake in San Fernando, California, Earthquake of February 9, 1971. Vol III (Geological and Geophysical Studies, pp. 69-122, U. S. Dept. of Commerce, 1973).

Tucker, B. E. and Brune, J. N., 1977. - Source mechanism and $m_{b}-m_{s}$ analysis of afteshocks of the S. Fernando earthquake. "Geophys. J. R. Astr. Soc."

Epstein, B. and Lomnitz, C., 1966. - A model for the occurrence of large earthquake. « Nature », 211, pp. 954-956, August 271966. 